\title{
Optimization of Polymerase Chain Reaction to Overcome Contamination of Deionized Water and Plumbing Premises By Pseudomonas spp. in Molecular Biology Laboratory
}

\section{Ali Bin Thani}

Biology Department, College of Science, University of Bahrain, Kingdom of Bahrain

\section{Abstract}

The purpose of the current study is to introduce specific optimization steps to overcome non-specific binding of primers to contaminating DNA. The applied modifications provide applicable solutions especially if large number of primer aliquots were contaminated and the cost to replace them is high. Several steps were taken

Corresponding Author:

Ali Bin Thani

abinthani@uob.edu.bh

Received: 18 September 2018

Accepted: 10 October 2018

Published: 15 October 2018

Publishing services provided by

Knowledge $\mathrm{E}$

(c) Ali Bin Thani. This article is distributed under the terms of

the Creative Commons

Attribution License, which

permits unrestricted use and

redistribution provided that the

original author and source are credited.

Selection and Peer-review under the responsibility of the Sustainability and Resilience Conference Committee.

\section{G OPEN ACCESS} to achieve complete mitigation of non-specific binding: reducing the concentration of both forward and reverse primers, reduction in the total number of PCR cycles from 35 to 25 , increasing the annealing temperatures, doing filter sterilizations ( $0.2 \mu \mathrm{m}$ Thermo Scientific polyethersulfone membrane) for the deionized water (DI) used in PCR and in certain cases reducing the extension time. The optimization steps carried in this work were successful in eliminating non-specific binding of primers to contaminating DNA found in primer aliquots.

Keywords: Plumbing Premises, Water Contamination, PCR, Pseudomonas, Deionized Water

\section{Introduction}

Contamination of piping and pluming premises with gram negative bacteria is well documented [1-3]. Among other gram negative bacteria, Pseudomonas species inhabit most of the water systems in both industrial and research laboratories [4]. Reports on enumeration of such species became basic routine in certain countries [4]. In University of Bahrain there is continues monitoring for changes in numbers of Pseudomonas in water systems. Premises at university use "deionization units" to provide required deionized water (DI) for laboratory procedures. Tested water samples showed high titers of isolated Pseudomonos spp. In both tap and deionized waters. 
Deionized water used in PCR is usually sterilized by autoclaving for 15 minutes at $121^{\circ} \mathrm{C}$ and 15 psi [5]. After autoclaving, heat-stable DNA from dead cells would contaminate subsequent processes such as PCR mixtures and primer aliquots. As a consequence of this step, nonspecific binding of primers due to contaminating DNA would result in false amplifications. The purpose of the current study is to introduce specific optimization steps to overcome nonspecific binding of primers to contaminating DNA coming from contaminated primer aliquots. The applied modifications provide applicable solutions especially if large number of primer aliquots were contaminated and the cost to replace them is high. An estimated cost for single primer would range between $\$ 10-35$. Thus for research projects that use a large number of primers, it would cost a lot to replace all primer aliquots contaminated with DNA.

\section{Protocol}

\subsection{Culture media for isolation of Pseudomonas Spp.}

Conventional isolation techniques (standard most probable number techniques) for isolation and enumeration of Pseudomonas bacteria were used [6]. Pseudomonas were cultivated on asparagine agar media for isolation and enumeration [6]. Other Conventional methods applied to test for presence of coliforms and other possible pathogenic species were carried out too [7].

\section{2. $P C R$ conditions}

The amplifications were carried using the KAPA2G Fast PCR kit under the following conditions (total reaction volume $25 \mu \mathrm{l}$ ): 0.5 units of KAPA2G Fast DNA polymerase, $0.2 \mathrm{mM}$ of dNTPS, $0.5 \mu \mathrm{M}$ forward and reverse primers. The PCR conditions were as following (TECHINE GENIUS thermocycler): initial denaturation at $95^{\circ} \mathrm{C}$ for 2 minutes, 35 cycles of 10 seconds at $95^{\circ} \mathrm{C}, 10$ seconds at $62^{\circ} \mathrm{C}$, and 1 second at $72^{\circ} \mathrm{C}$. Final extension was for 10 minutes at $72^{\circ} \mathrm{C}$.

\subsection{Gel electrophoresis}

$1 \%$ agarose was prepared for most amplification runs in this study. The gels were stained with ethidium bromide $(0.5 \mu \mathrm{g} / \mathrm{ml})$ for 30 minutes and de-stained before visualization. DNA ladder used is GeneRuler from Thermo Fisher Scientific. 


\section{Representative Results}

The optimization process started with the reduction in the concentrations of both forward and reverse primers (Figure 1-panel B). In the original protocol, the final concentration of both primers was $0.5 \mu \mathrm{M}$ [8] and was reduced to $0.1 \mu \mathrm{M}$. The intensity of the false bands was reduced but not eliminated (Figure 1-panel B). Then the following steps were performed, reduction in total number of PCR cycles from 35 to 25 , increasing the annealing temperatures (upon the Tm of primers), doing filter sterilizations ( 0.2 $\mu \mathrm{m}$ Thermo Scientific polyethersulfone membrane) for the deionized water (DI) used in PCR and in certain cases reducing the extension time (depends on product size). After applying these optimization steps, no non-specific binding was noticed (Figure 1-panel D).
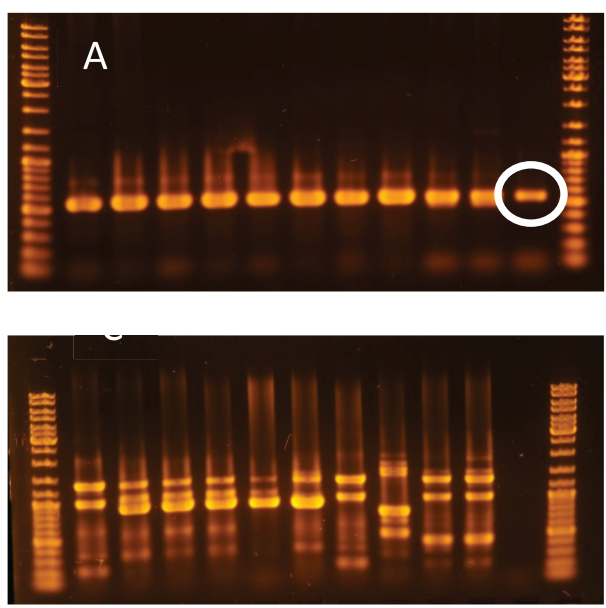
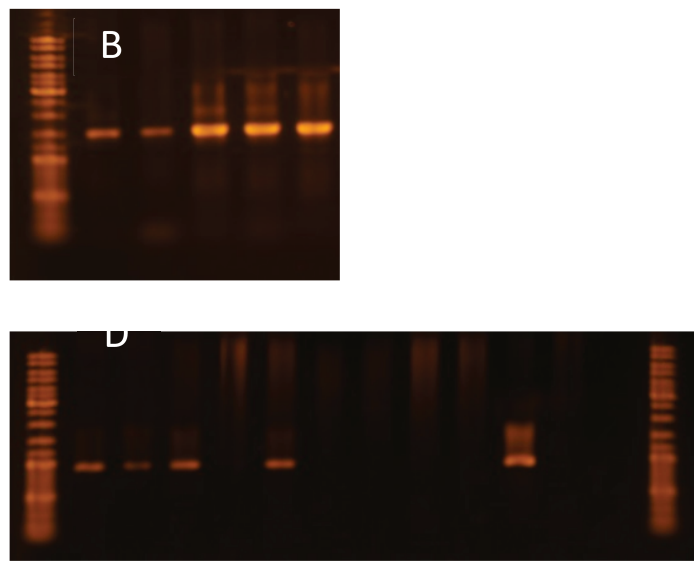

Figure 1: Panel A. Amplification of PCR products using autoclaved deionized water. The white circle shows the non-specific PCR product in the negative control. Panel B. A non-specific PCR amplicon produced in a negative control sample. In this part, different concentrations of primers were used (from left to right the concentrations of primers were: $0.1,0.2,0.3,0.4$ and $0.5 \mu \mathrm{M}$ ). Panel C. After the use of filter sterilized deionized waters (0.2 $\mu \mathrm{m}$ Thermo Scientific polyethersulfone membrane) no false amplifications were noticed in the negative control (last column). Panel D. The same amplification in panel C but after applying the optimization steps (e.g., reduction in total number of PCR cycles from 35 to 25 , increasing the annealing temperatures). DNA ladder used is GeneRuler from Thermo Fisher Scientific.

\section{Discussion}

Molecular diagnosis laboratories in hospitals and universities use deionization units to provide water for identification and detection of pathogens and reporting of human diseases [9]. However, as reported before these piping systems are considered the source of contamination for molecular diagnostics protocols as different bacterial populations inhabit these premises [9]. The current study shows the importance of using (0.2 $\mu \mathrm{m}$ ) filters to sterilize (DI) water. The study used $0.2 \mu \mathrm{m}$ filters instead of 0.45 
$\mu \mathrm{m}$ to avoid possible contamination of certain species of bacteria such as Mycoplasma, known to pass through the $0.45 \mu \mathrm{m}$ filters [10].

The study investigated the presence of Pseudomonas spp in water premises of University of Bahrain. However, other bacterial species were noted too (data not shown). No pathogenic or coliforms were detected with conventional procedures in samples studied.

The optimization process started with the reduction in the concentrations of both forward and reverse primers $0.1 \mu \mathrm{M}$. According to previous studies primer concentrations in PCR reactions are the most likely cause of non-reproducible amplifications and that most of these are dependent on primers' sequences [11]. However, further optimization steps were required to mitigate the effects of contamination. According to [8] the primers are not completely used up during the amplification. However, due to the accumulated products at the end of the amplification process the primers would straggle to find their target sequences. Therefore, to avoid high primer concentrations which might increase unspecific priming I reduced the number of PCR cycles to 25 instead of 35 (Figure 1-panels D). Reducing the number of PCR cycles has been found to enhance the amplification process and reduces the smear effects as can be seen in Figure 1-panels $C$ and $D$ [12]. The elimination of the non-specific binding was achievable after applying all optimization steps mentioned above and in certain cases reducing the extension time.

The optimization steps observed exclude the need for other methods previously applied to reduce reagents' contamination: UV and gamma radiations, DNase, restriction digests, plus other chemical treatments [13-20]. All of these methods come with drawbacks such as reduction in enzyme activity due to radiation or DNase treatments, or an increase in the amount of contaminating DNA if restriction enzymes were used [13-20].

The current investigation pinpoint to the importance for more controls and tests when working with culture independent methods as contaminants from different sources might intervene with the obtained results and subsequent analysis.

\section{Conclusion}

In the current study several steps were applied to reduce/eliminate the effects of contaminating DNA coming from deionized water. The optimization steps were successful to eradicate the effects of the contaminants; however, the optimization steps might not suite different amplification protocols such as multiplex PCR. Moreover, the 
optimization steps will not optimize for contaminants of the same species tested if the primer aliquots were the source of contamination.

\section{Disclosures}

I have nothing to disclose.

\section{References}

[1] Favero, M. S., N. J. Petersen, L. A. Carson, W. W. Bond, and S. H. Hindman. Gramnegative water bacteria in hemodialysis systems. Health Lab. Sci. 12 321-334., (1975).

[2] White, D. C., and M. W. Mittleman. in In Proceedings of the Ninth Annual Semiconductor Pure Water Conference, 17 and 18 January 1990, Santa Clara, Calif. 150-171.

[3] Matsuda, N., W. Agui, T. Tougou, H. Sakai, K. Ogino, and M. Abe. Gram-negative bacteria viable in ultrapure water isolated from ultrapure water and effect of temperature on their behavior. Colloids Surf. B Biointerfaces. 5 279-289, (1996).

[4] Kulakov LA, M. M., Ogden KL, Larkin MJ, O'Hanlon JF. Analysis of bacteria contaminating ultrapure water in industrial systems. Appl Environ Microbiol. 68 1548-1555, (2002).

[5] Raja, C. E. A., Kolandaswamy; Selvam, Govindan Sadasivam. Isolation and Characterization of A Metal-resistant Pseudomonas Aeruginosa Strain. World Journal of Microbiology and Biotechnology. 22 (6), 577-585, (2006).

[6] Hihgsmith, A. K. A., R.L. Evaluation of most-probable-number technique for the enumeration of Pseudomonas aeruginosa. Appl. Microbiol. 30 596-601., (1975)

[7] Grabow WOK, H. C. a. C. P. Evaluation of standard and modified M-FC, MacConkey, and Teepol media for membrane filteration counting of faecal coliforms in water. Appl Environ Microbiol. 42 192-199, (1981).

[8] T, C. High primer concentration improves PCR amplification from random pools. Nucleic Acids Res. 24 985-986, (1996).

[9] Salter S, C. M., Turek EM, Calus S, Moffatt M, Turner P, Parkhill J, Loman NJ and Walker AW. Reagent contamination can critically impact sequence-based microbiome analyses. BMC Biol. 12 87, (2014).

[10] Drexler., C. C. U. a. H. G. in Methods in Molecular Biology Vol. 946 1-13 (2013). 
[11] Hennessy L. K., T. J. a. K. C. \&. PCR conditions and DNA denaturants affect reproducibility of single-strand conformation polymorphism patterns for BRCA1 mutations. Clin. Chem. 44 879-882, (1998).

[12] Bell, D. A., \& DeMarini, D. Excessive cycling converts PCR products to random-length higher molecular weight fragments. Nucleic Acids Reseach. 19 5079, (1991).

[13] Rand KH, H. H. Taq polymerase contains bacterial DNA of unknown origin. Mol Cell Probes. 4 445-450, (1990).

[14] Deragon JM, S. D., Mitchell G, Potier M, Labuda D. Use of gamma irradiation to eliminate DNA contamination for PCR. Nucleic Acids Res. 18 6149., (1990).

[15] Sarkar G, S. S. Shedding light on PCR contamination. Nature. 343 27, (1990).

[16] Hughes MS, B. L., Skuce RA. Identification and elimination of DNA sequences in Taq DNA polymerase. J Clin Microbiol. 32 2007-2008, (1994).

[17] Corless CE, G. M., Borrow R, Edwards-Jones V, Kaczmarski EB, Fox AJ. Contamination and sensitivity issues with a real-time universal 16S rRNA PCR. J Clin Microbiol. 38 1747-1752., (2000).

[18] Klaschik S, L. L., Raadts A, Hoeft A, Stuber F. Comparison of different decontamination methods for reagents to detect low concentrations of bacterial 16S DNA by real-time-PCR. Mol Biotechnol. 22 231-242, (2002).

[19] Tamariz J, V. K., Prinz M, Caragine T. The application of ultraviolet irradiation to exogenous sources of DNA in plasticware and water for the amplification of low copy number DNA. J Forensic Sci. 51 790-794, (2006).

[20] Vaishampayan P, P. A., La Duc MT, Bargoma E, Benardini JN, Andersen \& GL, V. $\mathrm{K}$. New perspectives on viable microbial communities in low-biomass cleanroom environments. ISME J. 7 312-324., (2013). 